\title{
LOS MONÓLOGOS DE LA VAGINA Y HOMBRES EN ESCABECHE: REESCRITURA DE LA SEXUALIDAD FEMENINA COMO UNA LIBERACIÓN DE LOS TABÚES PATRIARCALES QUE HAN MANTENIDO A LA MUJER SUBYUGADA
}

\author{
Lai Sai Acón Chan
}

\begin{abstract}
RESUMEN
Este se constituye en el último de tres artículos en los que se divide el proyecto de investigación titulado El proceso de formación de la subjetividad femenina a través de su sexualidad, un proyecto del CIICLA (Centro de Investigaciones en Identidad Cultural Latinoamericana). Esta entrega en particular es un análisis de Los monólogos de la vagina y Hombres en escabeche a partir de la teoría psicoanalítica feminista de Julia Kristeva, Luce Irigaray y Hélène Cixous.
\end{abstract}

ABSTRACT

This is the last of three articles, all of which stemmed from The Process of Female Subject Formation Through Her Sexual Identity, a research project sponsored by the Program of Gender and Identity Issues from the CIICLA, an acronym in Spanish for Center of Research on Latin American Identity, a research center from the University of Costa Rica. This study is meant to analyze the Vagina Monologues and Hombres en escabeche with feminist psychoanalytical theories by Julia Kristeva, Luce Irigaray y Hélène Cixous in order to provide women with a voice.

Para contrarrestar los efectos opresivos y represivos de un patriarcado regido por la Ley del padre o el Nombre del padre, diversas feministas han fabricado sus propios códigos. Las teorías feministas post estructuralistas, cuyo énfasis lo constituye el posicionamiento de los sujetos masculino y femenino dentro de la estructura del lenguaje, servirán de marco para analizar las variadas estrategias utilizadas por sujetos femeninos en las obras literarias en cuestión para manifestarse en contra del falocentrismo que define la escritura como creación esencialmente masculina. En el marco de éstas teorías, la principal perspectiva la constituye el psicoanálisis feminista de las francesas Hélène Cixous, Luce Irigaray y Julia Kristeva, quienes, con sus teorías sobre la construcción del sujeto femenino, la reinterpretación de supuestos patriarcales y la escritura femenina, serán de vital importancia en este análisis de Los monólogos de la vagina y Hombres en escabeche como distintos ejemplos del proceso de subjetivización del ser femenino por medio de su sexualidad. 
Según diferentes escuelas de psicoanálisis, es el cuerpo lo que distingue al hombre de la mujer. Mientras que para Sigmund Freud la mujer es básicamente un hombre sin su pene, para Jacques Lacan, antiguo discípulo del anterior, lo que distingue al hombre de la mujer es la adquisición del lenguaje a través de ritmos corporales esenciales: Lacan creía que el lenguaje consciente de la comunicación habitual era el lenguaje del Patriarcado (Macaya 1992: 84). Para poder expresar la experiencia humana de la adquisición del lenguaje, Lacan postula que el ser humano debe pasar por dos órdenes o registros. El orden de lo imaginario se asocia a la etapa preverbal, en la cual el infante conecta sus necesidades y satisfacciones con el cuerpo materno y sus ritmos. Sus necesidades no verbales no siguen un patrón lineal. Por otro lado, cuando el infante entra al orden de lo simbólico, adquiere la palabra del Padre, la cual usa como un sistema de comunicación verbal con "signos organizados en estructuras lógico-sintácticas" (citado por Macaya 1992: 86). Es decir, estas estructuras siguen un patrón lineal y cronológico y, al ser aceptadas por el infante, señala, a la vez, su aceptación del Nombre del Padre y su renunciación a la madre y a sus ritmos internos.

Según algunas adherentes al feminismo post estructuralista, el discurso femenino está marcado por experiencias psicosexuales puramente femeninas; inclusive algunas de ellas se consideran experiencias bisexuales. Entre esas experiencias se pueden citar el orgasmo femenino (la jouissance), la menstruación, la penetración vaginal, el embarazo, el amamantar, el parto, las prácticas lésbicas y la menopausia. El hecho de que la mujer, y no el hombre, esté conectada a ciertos ciclos fisiológicos y a un ritmo creador propios de su sexo da pie para creer que esas experiencias pueden expresarse de maneras diferentes. Así, el monólogo interior y el discurso semiótico materno juegan un papel importante en la definición del concepto de discurso femenino. El discurso femenino es un discurso semiótico, como lo entiende Kristeva, un discurso ilógico de lo inconsciente, lo impulsivo, lo reprimido, lo transverbal, y lo atemporal (Macaya 1992: 87). Es decir, que debido a su naturaleza indómita, el discurso femenino se opone al discurso simbólico, lógico y coherente del patriarcado al manifestarse en sus brechas e inconsistencias. Contraria a Cixous y a Irigaray, Kristeva no cree en un lenguaje femenino, sino en un lenguaje subversivo. Su creencia de que el poder revolucionario de los aspectos marginales y reprimidos del lenguaje construye al sujeto hablante como un ser descentralizado, productivo e intertextual será muy útil en esta investigación.

Hélene Cixous, por su parte, propone su concepto de escritura femenina como el espacio para desafiar la ideología de la creación literaria del siglo diecinueve, la cual propone al escritor masculino como un dios creador, único capaz de inseminar la página con la tinta patriarcal, así como para subvertir el logocentrismo de Occidente basado en una organización binaria que privilegia al primer componente y margina al segundo (hombre/ mujer, blanco/ negro). Al proponer una escritura que manifieste la riqueza, la pluralidad y los ritmos internos propios de la sexualidad femenina (según ella bisexual, porque es capaz de reunir los contrarios en un solo cuerpo), Cixous se aleja del modelo patriarcal de formación de subjetividad y diferencia sexual. El concepto cixousiano de escritura femenina es esencialmente una relectura de los conceptos derridianos de la diferencia (la différance). Para Cixous, escritura y voz van juntas. La mujer hablante materializa sus pensamientos con su cuerpo. Pero esa voz es más que una manifestación física del cuerpo, es una manifestación de su psique: es la Voz de la Madre de la etapa pre-edípica y del orden imaginario del infante, que se contrapone al Nombre del Padre del orden simbólico.

Las constantes negativas de Cixous a escribir sus teorías y su preferencia por sugerirlas representan un ejemplo de su concepto de escritura femenina. La combinación de estilos 
poéticos y narrativos, la combinación de géneros literarios y no literarios con comentarios que asemejan conceptos teóricos constituyen la manera en que Cixous ejemplifica el más puro concepto de écriture feminine. Su estilo es, entonces, semiótico, contradictorio, caótico, como el orden imaginario. Al igual que Cixous, Luce Irigaray tiene un interés particular en la construcción de la identidad femenina fuera del modelo psicoanalítico patriarcal que hace creer a la mujer que el sexo femenino es una versión defectiva del masculino. Según ella, para hacerlo se necesita un lenguaje propio que le dé una identidad propia a la mujer, un nuevo lenguaje que cambie las prácticas sociales y las realidades socio-políticas. De Irigaray, por lo tanto, se utilizará su concepto de construcción de la subjetividad femenina a través de un lenguaje políticamente cargado. El propósito de los términos tabú, los temas biológicamente femeninos y la estructura orgásmica de las dos obras es sin lugar a dudas concebir un lenguaje femenino, subversivo y a la vez político. El análisis de sus funciones demostrará la lucha por el poder que el lenguaje en Los monólogos de la vagina y en Hombres en escabeche puede desatar si hay concientización entre la población femenina.

\section{Los monólogos de la vagina}

Según la línea de pensamiento de las feministas post-estructuralistas Kristeva, Cixous e Irigaray, Los monólogos de la vagina es una obra subversiva: desde el título, la estructura, y el contenido se aprecian las cualidades que hacen de ella un ejemplo de ese discurso revolucionario. El discurso emitido por una vagina solo puede ser semiótico, es decir, ilógico, porque procede de una parte de la anatomía que, si bien tiene su lenguaje propio en un sentido figurado, realmente no puede emitir palabras y mucho menos monólogos. Es inconsciente, impulsivo y reprimido porque procede de una región tabú. La escogencia del término "monólogo" tiene su propia interpretación también. El monólogo interior es asociado por lo general con los ritmos internos femeninos y con la supuesta falta de lógica y de linealidad del discurso femenino. De igual manera, la estructura de la pieza teatral es inconsistente. Carece de la clásica división de, digamos, un autor canónico como Shakespeare, en actos y escenas. Muy por el contrario, combina no sólo monólogos con extractos de entrevistas y hechos tomados de fuentes como periódicos y enciclopedias.

\subsection{El proceso de producción de la escritura femenina}

En cuanto a la temática explorada, la autora se concentra en experiencias puramente femeninas que giran alrededor de la vagina, como la maternidad, la penetración vaginal, el sexo entre lesbianas, la menstruación, el papanicolau y el orgasmo múltiple. Este es el primer componente del lenguaje subversivo y políticamente cargado que Cixous llamó écriture feminine. Otro de los componentes de este lenguaje femenino subversivo propuesto por Eve Ensler procede del cuerpo mismo: nombrar, gemir, pronunciar palabras tabú y mirar son manifestaciones de una escritura femenina. Dos mujeres en la obra utilizan la primera estrategia para reivindicar sus vaginas.

La mujer del "Club de la vulva" siempre ha estado obsesionada por darle nombre a todos los miembros de su colección de ranas y a partes de su cuerpo, pero es incapaz de 
darle un nuevo nombre a su vagina, que una de sus niñeras llamara "cosita". Al alcanzar la madurez sexual, se siente completamente cohibida de su ser sexual porque se siente poca cosa. Solo al rebautizar la vagina con un nombre más reivindicador es cuando se siente cómoda con su propia sexualidad y con su esposo:

\begin{abstract}
Y cantamos la canción de la vulva, la cual no tenía nada que ver con croar sino con besar, y bailamos la danza de la vulva, la cual no involucraba dar saltitos sino pasos, y todas las otras partes del cuerpo estaban alineadas-Betty y Gladis y Shorty_y ellas definitivamente estaban escuchando (Enler 2001: 90).
\end{abstract}

Del acto de nombrar emerge un nuevo lenguaje liberador que involucra varias partes del cuerpo y, por consiguiente, varios sentidos como ver, palpar y escuchar. Cuando la vagina es renombrada, la mujer adquiere una nueva identidad sexual.

La otra mujer que reivindica la vagina es la de "Reclamando panocha"1: "La llamo panocha. La he reclamado, a la 'panocha'. De verdad me gusta. 'Panocha'. Escucha como suena. 'Panocha"' (101). Su rebeldía se manifiesta en el desenfado con el que pronuncia una palabra tabú como "panocha”. Pero es también el nombramiento de otras palabras cuya primera letra comienza con los sonidos c, u, n y t, los componentes de la palabra "panocha" en inglés, que convierte el acto de nombrar en un acto de autogratificación o de jouissance:

\begin{abstract}
C C, Ca, Ca. Caverna, carcajear, clítoris, corronga, correrse - c cerrada — bien cerrada, dentro de la cadespués la u—después cu—curveada, invitando a la suave u—uniforme, "ubajo," "urriba" (deben pronunciarse guturalmente), urgencia, uh, uh—después sigue la n y cun es el resultado-letras apretándose juntas, acomodándose de lo más bien—n—nido, n'este momento, nexo, "nice," "nice," profunda y redonda n, cun, cun—n es un malvado impulso eléctrico que asierra, un ruido que taladra los oídos, después sigue una n suave, cálida — cun, cun, sigue la t—una t aguda y suculenta—-textura, tomar, tienda, tensa, tentadora, trepadora, tiempo, táctil, transmitir, testimoniar. Cuéntamelo, cuéntamelo "cunt cunt," dímelo, cuéntamelo "Cunt." "Cunt." (102).
\end{abstract}

La constante repetición de los fonemas que componen la palabra inglesa "cunt" es comparable a la bisexualidad inherente al ser humano, según Luce Irigaray en su artículo "This sex which is not one". Para Irigaray, la anatomía sexual femenina es mucho más compleja que la masculina. Para el hombre, el mayor placer sexual estriba en la estimulación de su pene, ya sea por métodos externos, como la mano, la vagina o el lenguaje. Mientras que el hombre necesita mirar y ser tocado para experimentar placer, la mujer, posee un órgano difícil de localizar visualmente, y compuesto por un clítoris, una vagina y un par de labios y otro par de labios menores que constantemente se tocan y que son capaces de producir auto-placer. La mujer que recita el cántico "Reclamando panocha" se satisface a sí misma con solo producir los sonidos y palabras afines al término "cunt." Poco a poco se auto-estimula hasta llegar a un paroxismo comparable a un orgasmo femenino, múltiple, no único, difuso, no enfocado y orientado hacia el proceso, no hacia la meta (Childers y Hentzi 1995).

Otro componente de tal escritura femenina es el acto de gemir. "La mujer que amaba hacer felices a las vaginas", obviamente una mujer lesbiana o bisexual, dice que gemir es una arma poderosa que asusta a los hombres pues los hace perder concentración durante su egoísta acto sexual. Avergonzada de sus gemidos, comienza a suprimirlos de su identidad sexual hasta que descubre que gemir no amenaza a mujer alguna, de modo que encuentra placer "descubriendo la llave, abriendo el cerrojo que aprisionaba la boca de la vagina, su voz, esta salvaje canción" (109). Además, esta mujer desafía el lenguaje políticamente correcto del patriarcado 
al referirse a vocablos y situaciones tabú en su taxonomía de gemidos: el de clítoris, el vaginal, el que combina ambas variantes, el jadeo, el bisexual, el orgásmico, el super orgásmico y otros. Gemir y nombrar lo innombrable se convierten en otros elementos del lenguaje femenino subversivo que Eve Ensler desencadena. En los dos casos, la escritura femenina se convierte en una especie de cántico mágico cuya intención es invocar la esencia misma de la cual están hechas las mujeres: su sexualidad.

\section{La mirada}

La acción de mirar es otro de los componentes del lenguaje políticamente cargado de Ensler. La mirada masculina es un término originalmente acuñado por teóricos cinematográficos, pero que últimamente ha sido apropiado por algunas feministas psicoanalíticas en el ámbito literario y de la crítica literaria, para referirse a aquellas representaciones de la mujer que la cosifican. Para Laura Mulvey, crítica cinematográfica británica, el filme "puede obligar a la espectadora a participar en su propia humillación, debido a que la organización técnica y la psicológica del clásico filme "hollywoodense" están basadas en el voyerismo y el fetichismo" (Guerin 1999: 206). Del mismo modo, en un texto patriarcal, el lector se identificará con el punto de vista masculino y eventualmente hasta llegará a sentir placer al mirar al objeto de deseo propuesto por el narrador.

Dicho tipo de espectador o lector que los filmes o textos patriarcales promueven puede contribuir a cosificar a algunos personajes al hacerlos objeto de una mirada controladora y curiosa, es decir, a la escopofilia (Childers y Hentzi 1995). Para contrarrestar esta práctica cosificante, algunos críticos han propuesto teorías de espectacularidad femenina y de identificación lesbiana. Curiosamente, uno de los sujetos que Ensler escoge para que represente esta nueva mirada que lejos de cosificar, subjetiviza, es un hombre. En "Porque a él le gustaba mirarla", Bob es un hombre ordinario, alguien que a primera vista no parecía un tipo interesante con el cual irse a la cama. Sin embargo, amaba las vaginas:

\footnotetext{
le encantaba la sensación, el sabor, el olor, pero lo más importante, le encantaba como se veían (...) se quedó mirando por casi una hora, como si estudiara un mapa, observara la luna, se fijara en mis ojos, pero era mi vagina lo que miraba. A la luz lo miraba mirándome, y estaba tan genuinamente excitado, tan pacífico y eufórico (55-7).
}

Es su mirada lo que transforma a la mujer amada en un ser autónomo, bello y seguro de sí mismo. En donde antes existiera una persona con baja autoestima sexual, surge un ser completo, deseante, satisfecho de su nueva sexualidad gracias a una mirada transformativa.

La relectura del concepto de especularidad femenina que Ensler hace en los Monólogos surge en otra escena, "El taller de la vagina". Esta vez, Ensler se vale de otra mujer insegura de su sexualidad, quien, auxiliada por un espejo, se redescubre como otro ser completo, deseante y satisfecho de su sexualidad en un taller precisamente diseñado para tal propósito: "Mi vagina me sorprendió. No pude hablar cuando me llegó el turno. No tenía palabras. Había despertado a lo que la mujer a cargo del taller llamara 'maravilla vaginal'. Tan solo quería yacer sobre mi colchoneta con mis piernas abiertas examinando mi vagina por siempre" (46). La metáfora del espéculo sirve para examinar las relaciones entre el Uno y el Otro. El Uno es aquel ser que necesita del Otro para definirse. De nuevo, el sexo que no es uno, según 
Irigaray. Por eso, la propuesta de que ambos son necesarios para alcanzar un balance que lleve a una identificación sexual positiva es fundamental.

La mirada de afuera nos define y limita en cierto modo, pero la mirada de adentro nos ayuda a completar esa parte de nuestra identidad que sentimos que falta, o viceversa. La mirada es tan fuerte que hasta se materializa en tacto: como la mujer del taller, quien por largo rato contemplara maravillada lo que constituía su ser hasta que decide palpar su vagina por primera vez y descubre que ella es su vagina y su vagina es ella:

(...) puse mi dedo sobre lo que repentinamente se había transformado en mí misma. Primero sentí un ligero estremecimiento que me impulsó a seguir. Entonces el estremecimiento se convirtió en un temblor, en una erupción, las capas dividiéndose y subdividiéndose (...) y sentí la conexión, la conexión de estar sobre mi colchoneta azul contorsionándome (50).

La mirada en los Monólogos no objetiviza porque no es una mirada típicamente masculina, no es visual en un cien por ciento sino que involucra los otros sentidos. La mujer del primer acto se olfatea, se siente, se degusta, se mira a través de la mirada de Bob, mientras que la mujer del taller se siente y escucha su yo interior a través de su mirada.

\section{Hombres en escabeche}

Aunque mucho más sutil que en los Monólogos, las imágenes que componen el lenguaje subversivo y políticamente cargado de Hombres en escabeche demuestran la preocupación de Ana Istarú por instaurar un lenguaje que exprese inquietudes femeninas acerca de su identidad sexual. El título parece expresar el deseo de Alicia por preservar a los hombres de su vida tal y como los conoce en las primeras etapas de cada relación, pero es en realidad un intento por regresar a la etapa pre-edípica lacaniana.

La imagen del hombre en escabeche es un eco de un feto bien acomodado en el cálido vientre materno, rodeado del líquido amniótico vital. Preservar a los hombres en escabeche es, pues, un intento por regresarlos al período de sus vidas en que la figura femenina y la voz materna lo eran todo y la Ley del Padre aún no había perturbado su esencia acomodada a los ritmos internos y sonidos de la madre. El lenguaje femenino subversivo en la obra se compone básicamente del formato de monólogo intercalado con diálogo, la combinación de pasado con presente, términos clínicos del psicoanálisis, recuentos de experiencias sexuales como la menstruación, el acto sexual y el embarazo, lenguaje tabú e invocaciones a antecesoras femeninas míticas.

\subsection{Monólogo ïinterior?}

La obra comienza como un monólogo, el de una Alicia vestida como una novia y esperando por un hombre, el "hombre de su vida". La protagonista comienza a hablar dirigiéndose al público de una manera que implica monólogo porque es el único personaje sobre el escenario, y diálogo, porque está consciente de su audiencia. Esta dualidad se repite a lo largo de la obra en diferentes formatos. Aunque en ocasiones hay hasta dos personajes en escena, el otro personaje es invocado solamente por el recuerdo de Alicia. Así, aunque existen 
momentos en que el diálogo prevalece, el espectador debe recordar que es producto de retrospectivas que se dan en el monólogo de Alicia. El poder de su constante monologar es tal que invoca a siete hombres distintos que en algún momento influyeron en su vida. El monólogo también rompe con la estructura lineal del tiempo, haciendo posible un fluir entre presente y pasado, pasado y presente sin que medien divisiones más visibles tales como escenas. De esta manera, el monólogo en la obra surge como un ejemplo de ese lenguaje revolucionario, semiótico, ilógico, políticamente cargado que se suscita a causa de los ritmos internos del cuerpo femenino.

Curiosamente, y al igual que los Monólogos de Eve Ensler, Hombres en escabeche tiene como uno de los temas principales la identidad sexual femenina, identidad que surge solo tras un análisis profundo de los ritmos femeninos que marcan a la protagonista como mujer y que la vinculan a sus hombres en escabeche. Sus monólogos sobre la envidia del pene que la hacen sentir como un ser incompleto, la llegada de la menstruación que reprime su identidad femenina, su infeliz despertar sexual ante un hombre, su agridulce embarazo por el hombre que ama pero que no puede comprometerse y el doloroso aborto involuntario son componentes de su lenguaje de lo inconsciente, porque proviene de la interioridad femenina; de lo reprimido, porque se trata de tabúes sexuales deseosos de salir a la superficie; de lo transverbal, porque proviene del cuerpo mismo de la mujer; y de lo atemporal, porque el relato rompe con la estructura cronológica de relatos más tradicionales.

Aunque en la primera parte de la obra de teatro, Istarú retrata a una angustiada Alicia que se ha dado cuenta de que carece de pene, su marginalidad va encontrando una forma de expresión en su monólogo en retrospectiva, en las memorias de todos aquellos acontecimientos que la marcan como un ser en busca de su identidad sexual. La obra en sí es como el diccionario de los horrores del monje loco, pues alude a una gran gama de experiencias claves en la conformación de una identidad como ser sexuado: desde uno de los clásicos del psicoanálisis freudiano, tal como la envidia del pene, pasando por las clases de educación sexual en el colegio, las películas pornográficas por la televisión, los mitos infantiles sobre la concepción, hasta la doble moral que promueve la virginidad femenina pero condona la sexualidad masculina, que aplaude a los hombres que "mientan a la madre" y reprueba a las niñas malhabladas.

\subsection{Escritura femenina}

Nombrar constituye, como en los Monólogos, un componente del lenguaje femenino subversivo. Alicia nombra lo innombrable y lo reprimido de muchas maneras creando un lenguaje que expresa lo que el lenguaje irónicamente lineal del patriarcado oculta. Para referirse a palabras o situaciones tabú a veces utiliza eufemismos, otras veces utiliza palabras cultas, pero jamás se adhiere a un solo formato. Cuando utiliza eufemismos, el efecto es tan cómico que más bien provoca identificación con su lenguaje marginal: las galleticas de maicena (senos), la espada de fuego de San Miguel Arcángel (el placer de la penetración), el spaghetti alla putanesca (una perdida que goza haciendo favores sexuales), San Clítoris Arcángel (el orgasmo femenino), la retahíla de filósofos clásicos (el clímax del hombre), comerse al novio sin cubiertos ni mostaza (ser una mujer liberada o perdida), consumir hombres sin filtro (tener relaciones sexuales sin condón), el pájaro azul del territorio de los sueños (el pene), el elefantito de Andrés (el pene de su hermanito), vástago de meretriz, hijo de la gran . . . Bretaña. 
Cuando, debido a restricciones impuestas sobre señoritas decentes, Alicia utiliza palabras cultas de diccionario para referirse a seres humanos que trafican con el sexo (el proxeneta y la hetaira o meretriz) o para nombrar partes de la anatomía sexual humana, el efecto es todavía más jocoso porque no es la norma. La misma Alicia las identifica como términos salidos del diccionario del monje loco: himen, falo, glúteo, vulva, labios, clítoris, vagina, útero, trompas, ovarios, testículos, palabras horrorosas, feas y más complejas que un atlas ilustrado, según Alicia. Otras maneras de nombrar son la recitación del santoral y la invocación de antepasadas femeninas. Alicia clama por la ayuda del santoral católico, no tanto para soportar su primera experiencia sexual, sino para acallar sus gemidos de placer. Ella sabe que, como católica devota y religiosa, primero, no debería estar en el apartamento de soltero del filósofo; segundo, no debería acceder a su iniciación sexual; y, por último, no debería mostrar gozo por la experiencia.

La confusión de nombres que el padre crea cada vez que la ve, llamándola de una manera distinta, provoca en Alicia una ira tal, que exasperada pronuncia una retahíla de nombres de féminas ambiguas, reprobadas por el Nombre del Padre pero reivindicadas por la Voz de la Madre, como Lucrecia Borgia, Circe, Morgana, Dalila, Medea. Alicia es un ángel caído, una mala mujer solo por el hecho de haber desafiado el sistema patriarcal. Al llamar a cada una de esas mujeres por su nombre, Alicia convoca a la diosa que vive dentro de ella y da vida a esas antepasadas, hermanas de infortunio y estigma social, quienes al desafiar tiempo y espacio, se reúnen con su descendiente femenina y evocan un regreso a las sociedades matriarcales previas al patriarcado de Occidente. Reinscribir su historia a la luz de experiencias femeninas es una de las funciones primordiales del lenguaje corporal, subversivo, político de la mujer, como lo demuestran los monólogos, las experiencias, los nombramientos y las invocaciones.

El concepto de escritura corporal de la Cixous, el lenguaje revolucionario de Kristeva y el lenguaje político de Irigaray se juntan en un solo proceso de reescritura de la sexualidad femenina que persigue como objetivo liberar a la mujer de los tabúes sociales que la han mantenido en una posición inferior. La reescritura que hacen Ensler e Istarú de supuestos patriarcales se convierte en una poderosa herramienta textual para sobrepasar restricciones lingüísticas, físicas y emocionales en torno a la identidad sexual de la mujer y un medio catártico que provea a la mujer de una voz y una identidad sexual sólida. El uso abierto de términos sexuales y otras palabras tabúes, el desarrollo de temas ligados a la anatomía sexual femenina y la estructura poco convencional en obras de teatro que se asemejan a los orgasmos múltiples asociados con la mujer, son expresiones de un lenguaje esencialmente mujeril, que promueve la multiplicidad y no la singularidad, la diseminación y no la inseminación enfocada, el proceso y no la meta.

\section{Notas}

1. Decidí traducir el vocablo "cunt" como panocha porque "cunt" es una palabra vulgar que se usa en los Estados Unidos para denominar a la vagina o para referirse al sexo. Emplear un vocablo tan neutral como vagina no sería del todo exacto y le quitaría precisión al significado real. 


\section{Bibliografía}

Childers, Joseph and Gary Hentzi (eds.). 1995. The Columbia Dictionary of Modern Literary and Cultural Criticism. N.Y.: Columbia University Press.

Cixous, Hélène. 1991. "The Laugh of the Medusa". En Warhol, Robin R. and Diane Prize Herndl (eds.).

Ensler, Eve. 2001. The Vagina Monologues: The V Day Edition. New York: Villard.

Fe, Marina. 1999. Otramente: lectura y escritura feministas. México: Fondo de Cultura Económica.

Gilbert, Sandra and Susan Gubar. 1991. "Infection in the Sentence: the Woman Writer and Anxiety of Authorship". En Warhol, Robin R. and Diane Prize Herndl (eds.).

Guerin, Wilfred L. et al. (eds.). 1999. A Handbook of Critical Approaches to Literature. 4th ed. NY: Oxford University Press.

Irigaray, Luce. 1991. “Another 'Cause'—Castration.” En Warhol, Robin R. and Diane Prize Herndl (eds.).

1998. Ser dos. Buenos Aires; Barcelona; México: Paidós.

1991. "This Sex Which is Not One”. En Warhol, R. and Diane Prize Herndl (eds.).

Istarú, Ana. 2001. Baby Boom en el paraíso/Hombres en escabeche. San José: Editorial Costa Rica.

Jackson, Stevi (ed.). 1993. Women's Studies: Essential Readings. New York: New York University Press.

Jones, Ann Rosalind. 1991. "Writing the Body: Toward an Understanding of l'ecriture feminine." En Robin R. Warhol and Diane Prize Herndl (eds.).

Kristeva, Julia. 1980. Desire in Language: A Semiotic Approach to Literature and Art. Oxford: Blackwell.

Macaya, Emilia. 1992. Cuando estalla el silencio: para una lectura femenina de textos hispánicos. San José: Editorial de la Universidad de Costa Rica.

Martin, Emily. 1993. "The Woman in the Body”. En Jackson, Stevi (ed.). New York: New York University Press. 
Warhol, Robin R. and Diane Prize Herndl (eds.). 1991. Feminisms: An Anthology of Literary Theory and Criticism. New Brunswick, N.J.: Rutgers.

\section{Sitios}

Elam, Diane. 1997. "Feminist Theory and Criticism: Poststructuralist Feminisms". The John Hopkins Guide to Literary Theory and Criticism. Michael Groden and Martin Kreiswirth (eds.). www.press.jhu.edu

Klages, Mary. 2001. Poststructuralist Feminist Theory, Hélène Cixous: The Laugh of the Medusa. Conferencia. Department of English, University of Colorado at Boulder. http://www.colorado.edu/English/engl2010mk/cixous.lec.html

25 oct. 2001. Poststructuralist Feminist Theory, Luce Irigaray: This Sex Which is Not One. Conferencia. Department of English, University of Colorado at Boulder. http://www.colorado.edu/English/engl2010mk/irigaray.lecture.html

O’Grady, Kathleen. 1996. Guardian of Language: An Interview with Hélène Cixous. http://www.english.ucsb.edu/faculty/ayliu/research/grady-cixous.html

Oliver, Kelly. "Kristeva and Feminism”. Feminist Theory Website. Center for Digital Discourse and Culture at Virginia Tech University. www.cddc.vt.edu/feminism/Kristeva.html

Zivancevici, Nina. 2001. “An Interview with Julia Kristeva.” NY Arts Magazine. (MarchApril). http://nyartsmagazine.com/57/juliakristeva.html 